\title{
Fortification of soy milk with prebiotic natural $\beta$-glucan derived from edible mushrooms Pleurotus ostreatus and Agaricus bisporus
}

\author{
Kumaresan Kuppamuthu*, Swathi Gopalakrishnan, Raghuvandhanan K. Sivasamy, Thirumurugan Alagu, Sathishkumar \\ Thiyagarajan \\ Biochemistry and Microbiology Laboratory, Department of Biotechnology, Post Box No:2034, Kumaraguru College of Technology, Coimbatore, Tamil \\ Nadu -641049, India.
}

\section{ARTICLE INFO \\ Article history: \\ Received on: June 04, 2021 \\ Accepted on: September 31, 2021 \\ Available online: January 07, 2022}

\section{Key words:}

Fortification, $\beta$-glucan, prebiotics, Pleurotus ostreatus, Agaricus

bisporus, soy milk

\section{ABSTRACT}

Hot water extraction of edible mushrooms Pleurotus ostreatus and Agaricus bisporus at $90^{\circ} \mathrm{C}$ for 4 hours yielded a polysaccharide fraction containing crude $\beta$-glucan. Qualitative and quantitative analyses of the samples were carried out to identify the presence and abundance of carbohydrates. Diethylaminoethyl (DEAE) Sephacel column chromatography followed by affinity chromatography in an agarose-bound Concanavalin A column resulted in purified $\beta$-glucan. $\beta$-glucan was confirmed through the presence of unique functional groups present in it by using the Fourier transform infrared spectrum technique. Soy milk fortified with $\beta$-glucan was formulated, and this can alleviate the rate of obesity and related diseases caused by high calorific carbonated beverages. The further scope of the study involves sensory analysis and commercialization of the product.

\section{INTRODUCTION}

High calorific carbonated beverages are the most popular drinks in the present-day young generation. This is attributed to the fact that it is presented with many value additions like natural flavors, vitamins, minerals, and caffeine. Weight gain, hunger response stimulation, and ghrelin release-induced obesity are said to be the effects of carbon dioxide present in a lot of beverages [1]. The sudden increase in type 2 diabetes and obesity rate among people is directly linked to the consumption of these beverages. This is mainly due to the excess non-satiating sugar content present in these drinks [2]. These beverages are placed last or in level six in US guidance systems for beverage consumption. This system of grading beverages is based on their relative caloric content, health, nutritional benefits, and hazards [3]. The flavored milk available in the market is sweetened by the addition of artificial high caloric sweeteners. These artificial sweeteners are the leading cause of obesity and other health hazards [4].

\footnotetext{
*Corresponding Author

Kumaresan Kuppamuthu, Biochemistry and Microbiology Laboratory, Department of Biotechnology, Kumaraguru College of technology, Coimbatore, India.E-mail: kumaresan.k.bt@ kct.ac.in
}

Soy milk-based beverages can be touted as a healthier alternative for these high caloric beverages. Soy milk itself is a natural source of fats, proteins, carbohydrates, and some of the essential nutrients [5]. It is produced from soaked soybean. Plant-based milk serves as one of the substitutes for milk from cows, providing nutrients for lactose intolerant individuals and to people that are allergic to cow milk proteins [6]. The hypolipidemic effect of soy milk is gaining interest for its prospective role in lipid metabolism along with high-quality proteins, saponins, polyunsaturated fatty acids, phytosterols, isoflavones, and soy lecithins, and a variety of nutrients [7]. The lipid profiles of hypercholesterolemia patients can be improved with daily consumption of $\geq 25 \mathrm{~g}$ of soy protein with its supplementary phytochemicals [8]. The soy milk consumption also showed a notable increase in the quantitative insulin sensitivity check index and a significant decrease in the insulin resistance score - Homeostatic Model Assessment of Insulin Resistance (HOMAIR), and serum insulin level, which had beneficial effects on Systolic blood pressure (SBP), and Diastolic blood pressure (DBP) in patients with Nonalcoholic fatty liver disease (NAFLD) [9]. Perfect value addition in terms of nutrients and flavor will boost its marketability across all cohorts. Value addition to soy milk is highly favored by its ability to act as a vector for carrying many flavors, 
vitamins, and minerals. Furthermore, the fortification is easier and it can be consumed regularly and consistently.

The selection of fortificants plays a substantial role in the marketability of the product. Proper choice of the chemical structure of the fortificant is based on its cost, bioavailability in diet, and customer's acceptance of the sensory changes in the food. In this context, $\beta$-glucan, a soluble dietary fiber, presents in various natural sources such as plants, certain cereals, fungi, and algae can be an excellent choice of fortificants [10]. Besides being a good choice of fortificant, $\beta$-glucan can also act as a prebiotic element in the drink [11]. This non-digestible polysaccharide is a potential diabetic [12], cholesterol level regulator [13], has immune-modulating effects, and prevents obesity [14]. A good quality $\beta$-glucan can be extracted from various sources, but obtaining it from edible mushrooms makes it ideal to be added as a fortificant. Mushrooms have a variety of polysaccharides such as hemicellulose, galactans, mannans, xylans, chitin, and glucans [14]. Most cultivated mushroom species like Pleurotus ostreatus and Agaricus bisporus contain high protein and polysaccharides (glucans) $[15,16]$. Mushroom-derived polysaccharide exhibits immunomodulation, antioxidant, anti-inflammatory, and analgesic properties [17-19]. The use of palm sugar as a natural sweetener could be an excellent alternative considering the effects of artificial sweeteners. Palm sugar contains insoluble fibers, which increases the drink's prebiotic activity and imparts a flavor to the drink [20]. This study is concerned about the source and significance of $\beta$-glucan and its impact as a fortificant for soy milk.

\section{MATERIAL AND METHODS}

\subsection{Sample Collection and Preparation}

Pleurotus ostreatus was purchased from Grand Fresh Mushroom Farm located in the Western Ghats of Kerala. Agaricus bisporus was purchased from a local market, Sri Vinayaga Mushroom in Coimbatore, Tamil Nadu. Caps and stems of $75 \mathrm{~g}$ P. ostreatus and $65 \mathrm{~g} A$. bisporus were subjected to shade drying and then powdered using a mixer. The powdered mushrooms were sieved to remove impurities and were taken for further analysis. Dried soybeans (glycine max) were collected from a local market in Coimbatore, Tamil Nadu. About one cup of dried soybeans was soaked in a fivefold volume of distilled water for 18 hours at room temperature [21], blended with $3 \times$ ultra-pure water, and strained to collect soymilk. The palm sugar used as an alternative for artificial sweeteners was procured from local farms.

\subsection{Hot Water Extraction}

A quantity of $7 \mathrm{~g}$ each of the prepared samples of $P$. ostreatus and $A$. bisporus was suspended in sterile water in the ratio of $1: 10 \mathrm{w} / \mathrm{v}$. Hot water extraction of polysaccharides was carried out for 4 hours at $90^{\circ} \mathrm{C}$ [22]. The samples were drawn out at 1-hour intervals and the resultant slurry was cooled to room temperature and centrifuged at $10,000 \mathrm{rpm}$ for 30 minutes. The supernatant containing water-soluble polysaccharides was filtered through a paper filter, and the filtrate was concentrated using a rotary flash evaporator. The concentrated extract was powdered using a lyophilizer (Sub-Zero, Chennai). In total, $4.78 \mathrm{~g}$ was obtained and this was used for further tests.

\subsection{Qualitative and Quantitative Tests}

$0.1 \mathrm{~g}$ of mushroom extract was made up to $1 \mathrm{ml}$ with distilled water and was subjected to qualitative analyses such as Molisch's test, Barfoed's test, and Benedict's test to confirm the presence of carbohydrates (polysaccharide extract) in the sample. Iodine test was carried out to confirm the absence of starch in the polysaccharide extract. Di-nitro salicylic acid tests [23] and phenol sulfuric acid test [24] were carried out to estimate the amount of reducing sugars and total carbohydrates present in the sample.

\subsection{DEAE Chromatography}

To remove the proteins in the sample obtained from hot water extraction, the concentrated extract was subjected to DEAE chromatography Sephacel column. For this, $1 \mathrm{~g}$ of recovered supernatant was dissolved in $100 \mathrm{~mL}$ of distilled water and neutralized with $2 \mathrm{M} \mathrm{NaOH}$. In DEAE sephacel anion exchange column, the unbound fraction containing glucan was separated with 3-bed volumes volumes of $10 \mathrm{mM}$ phosphate buffer at $\mathrm{pH}$ 8.0

\subsection{Affinity Chromatography in Agarose-Bound Concanavalin A Column}

Con A agarose appears to selectively remove contaminants like mannan and glycosylated proteins from the sample [25]. The eluted glucan from the Sephacel column was applied to the Con A column $(1.5 \times 10 \mathrm{~cm}$, Aristogene, Bangalore $)$ to remove mannan from the glucan. The sample was concentrated using a rotary evaporator and then dissolved in $10 \mathrm{ml}$ of $50 \mathrm{mM}$ phosphate buffer (pH 7.4) containing $0.15 \mathrm{M} \mathrm{NaCl}$. The unbound fractions (glucan) were eluted with $50 \mathrm{ml}$ of the buffer prepared with autoclaved distilled water and collected as separate fractions. $50 \mathrm{ml}$ phosphate buffer ( $\mathrm{pH} 7.4$ ) containing $0.5 \mathrm{M}$ methyl mannoside and $0.25 \mathrm{M}$ $\mathrm{NaCl}$ was used to elute the bound mannan in the column and to regenerate it [25].

\subsection{Fourier Transform Infrared Spectrum (FTIR) Analysis}

FTIR (Shimadzu, Japan) analysis was carried out to visualize bonds present in the molecule. The identical infrared spectrum will not be produced by two exclusive molecular structures. This makes FTIR spectroscopy beneficial for several analyses. Therefore, the pure $\beta$-glucan extract obtained was subjected to FTIR analysis and functional groups were analyzed to confirm the presence of $\beta$-glucan [26].

\subsection{Preparation and Formulation of Value-Added Milk}

About one cup of dried soybeans was soaked in a fivefold volume of distilled water for 18 hours at room temperature [21], blended with $3 \times$ ultra-pure water, and strained using a muslin cloth to squeeze the soymilk out. Furthermore, it was heated over a low flame and brought to a boil, after which flavor, salt, and palm sugar were added and it was kept at a simmer for 20 minutes to mellow out the flavors. Palm sugar was added to soy milk as a natural sweetener. A purified $\beta$-glucan sample was added to soy milk in the ratio of 1:40. Palm sugar was ground and varied concentrations were added based on the degree of sweetness and 
aesthetics. $0.5 \mathrm{~g}$ of iodized salt per $100 \mathrm{ml}$ was also added to enhance the taste.

\section{RESULTS AND DISCUSSION}

Fresh $P$. ostreatus and A. bisporus were purchased and shadedried. The dry weights were found to be $30.6 \%$ and $28.3 \%$ of the original weight. The dried samples were then powdered. Shade drying was preferred because, in other drying methods, the possibility of components loss from the substances is high and in order to preserve the carbohydrate content [27]. Mushroom has the property of losing their color and texture when exposed to direct sunlight. Therefore, shade drying is preferred over sun drying in the case of mushrooms. Shade drying also ensures a good end product appearance to the mushroom species [28]. Hot water extraction of the mushroom sample was carried out for 4 hours. The samples were drawn at 1-hour intervals, and it was found that no charring occurred even after 4 hours of the extraction procedure. Since the extract has to be used in the food industry, no types of organic solvents were used as organic solvents are generally considered to be hazardous. Besides, this extraction procedure yielded a high amount of crude polysaccharides. The obtained recovery was $68.3 \%$

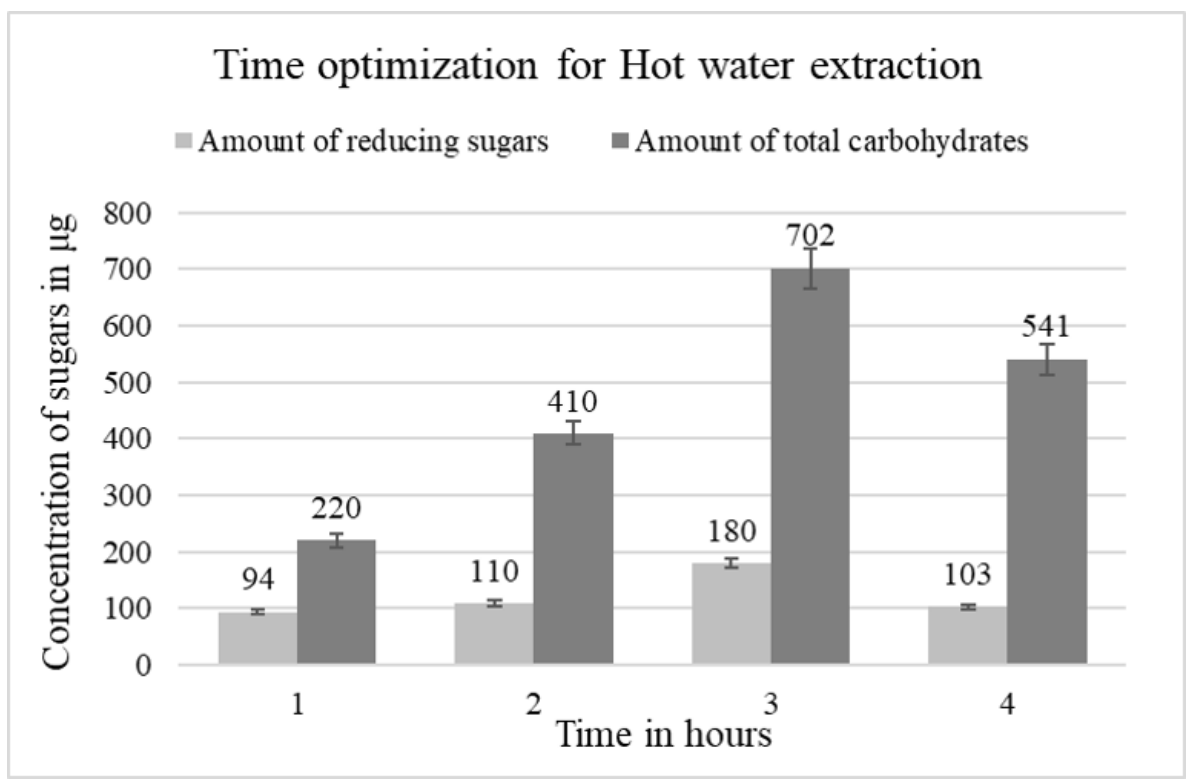

Figure 1: The graph represents the optimized time for hot water extraction of $P$. ostreatus.

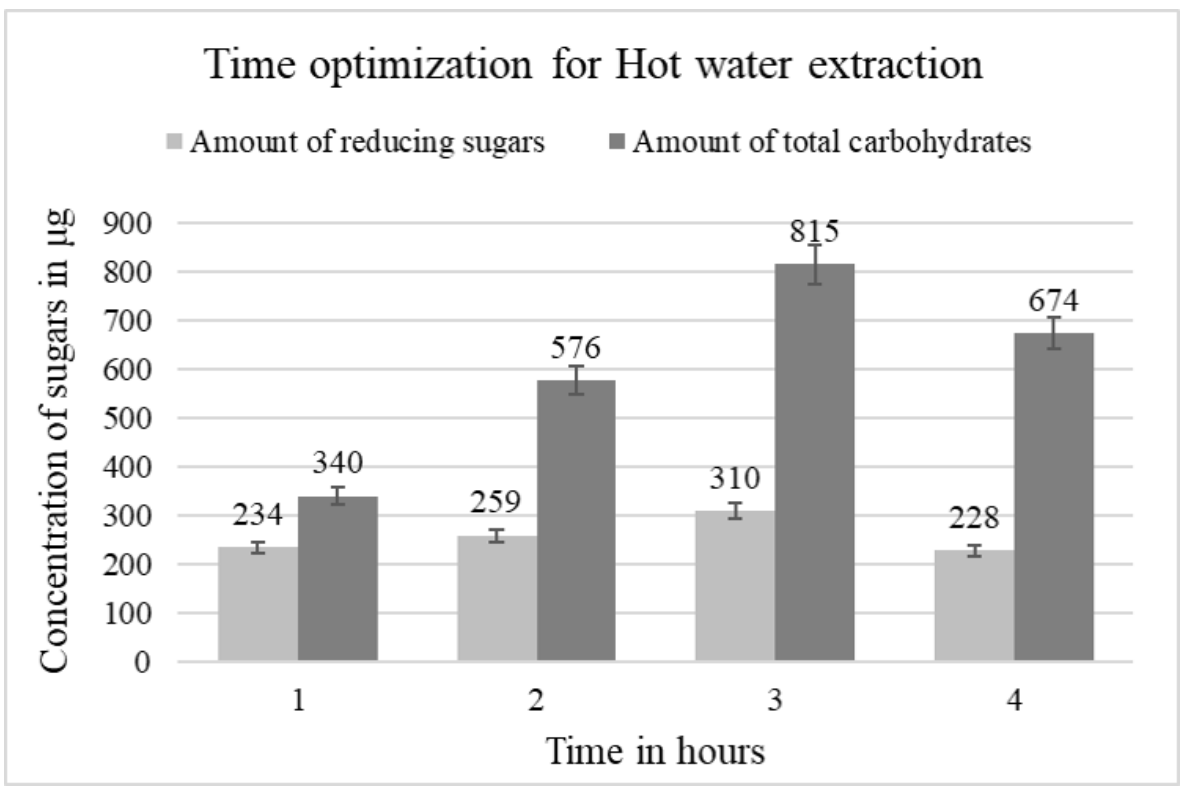

Figure 2: The graph represents the optimized time for hot water extraction of A. bisporus. 


\subsection{Qualitative Tests}

Molisch's, Barfoed's, and Benedict's tests yielded positive results signifying that it is a carbohydrate. The results obtained were in accordance with previous literatures [29-31]. Since $\beta$-glucan is a non-starch polysaccharide, it is crucial to test the absence of starch to continue working for large-scale industrial production of valueadded milk. Therefore, iodine test was carried out and yielded a negative result which was formerly reported [32,33], thereby confirming the absence of starch in the hot water sample.

\subsection{Quantitative Estimation}

The carbohydrate concentration in the samples was found using the standard graph. Based on the concentration, the time was optimized for hot water extraction (Figs. 1 and 2) and the maximum release of carbohydrate was found to be in the third hour for both mushrooms. Furthermore, the concentration of total carbohydrates was found to be higher in A. bisporus than P. ostreatus (see Figs. 1 and 2).

\subsection{Purification of Polysaccharide Extract}

The sample was purified using DEAE chromatography. After recovering the unbound samples containing glucan from the column, elution of the residual proteins was accomplished by adding phosphate buffer to the sample. The potassium and chloride ions present in the buffer will attach to the resins and expel the proteins out of the column [25]. Quantitative estimation of the residual proteins eluted from the DEAE column by Folin-Lowry's method was carried out to ensure the removal of protein from the sample. This is shown in Figure 3. DEAE chromatography method was preferred because of its high protein-binding capacity, good sensitivity, and minimal sample loss over the other purification techniques. Furthermore, to get purified $\beta$-glucan, affinity

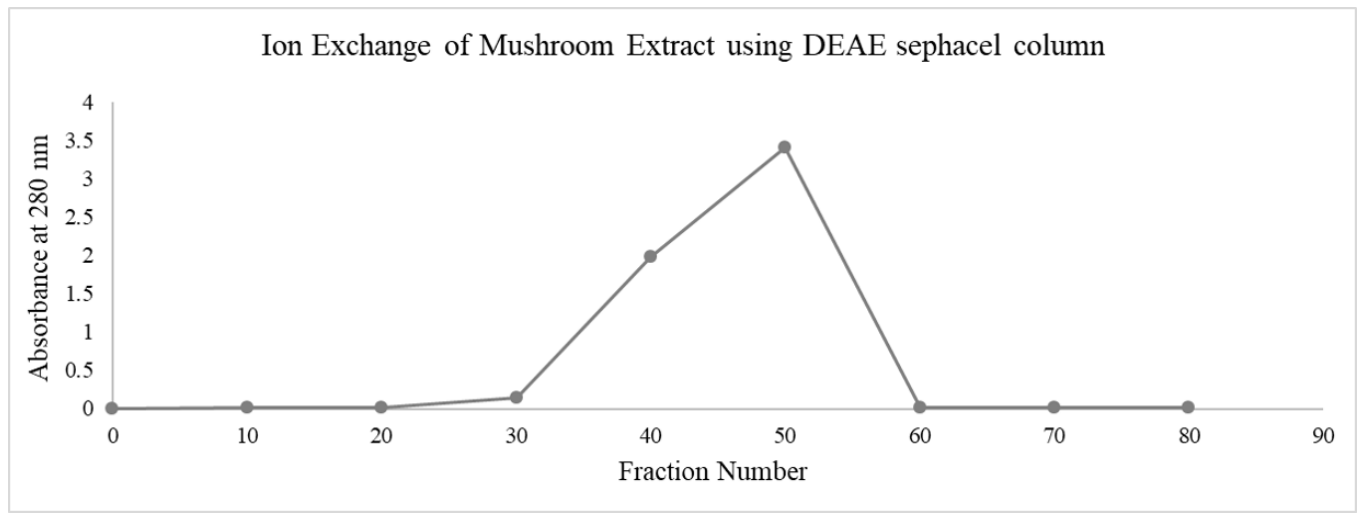

Figure 3: Protein measurements carried out by using ion exchange DEAE Sephacel column.

ФSHIMADZU

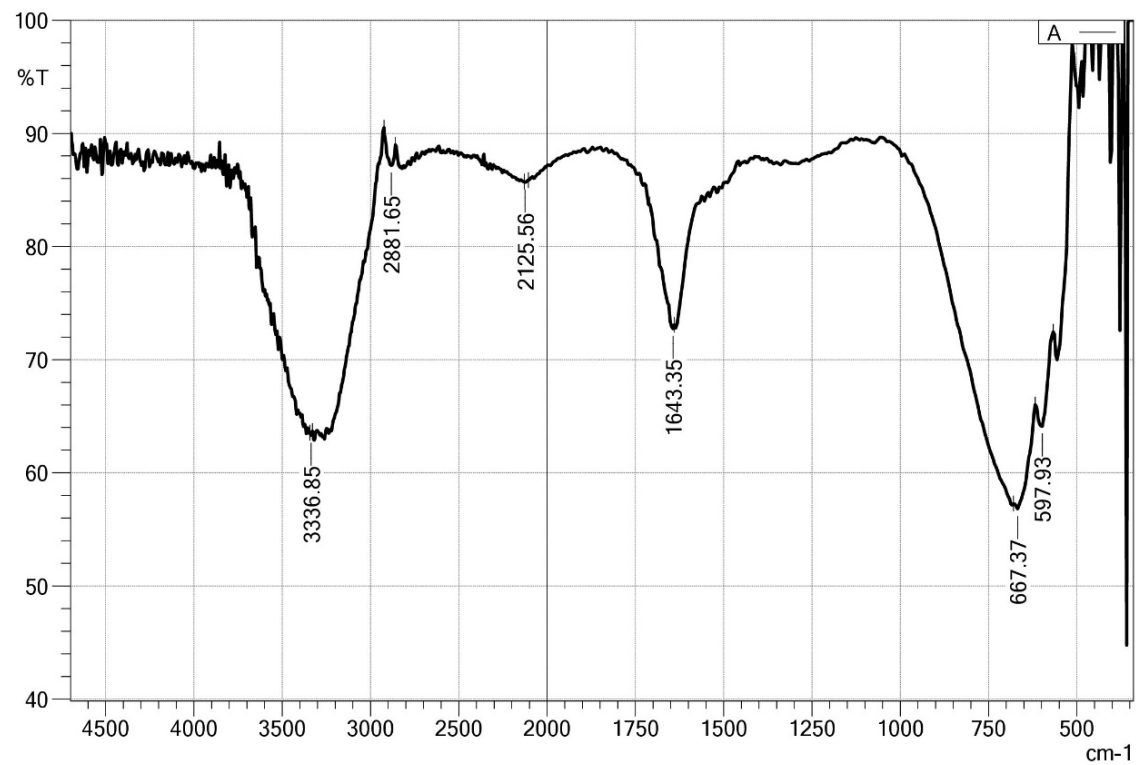

D:¥Sample Internal¥BT¥Kumaresan¥Swathi G¥A.ispd

Figure 4: FTIR analysis of the $\beta$-glucan extract from $A$. bisporus. 


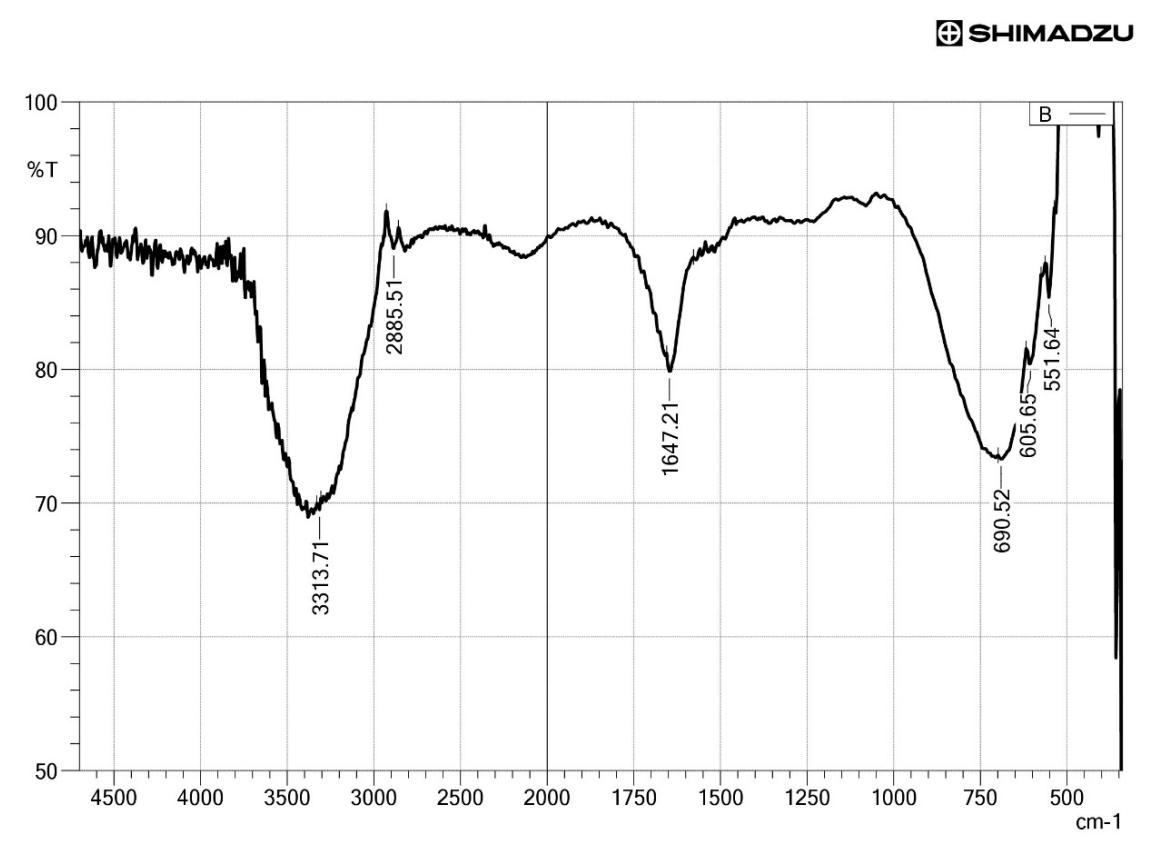

D:¥Sample Internal¥BT¥Kumaresan¥Swathi G¥B.ispd

Figure 5: FTIR analysis of the $\beta$-glucan extract from $P$. ostreatus.

Table 1: Comparison of main peaks of the FTIR spectra of A. bisporus and P. ostreatus.

\begin{tabular}{cccc} 
Functional groups & Wavenumber $\left(\mathbf{c m}^{-1}\right)$ & Wavenumber $\left(\mathbf{c m}^{-1}\right)$ of $\beta$-glucan sample \\
& & A. bisporus & P. ostreatus \\
$-\mathrm{OH}$ (Hydroxyl and alcohol) & $3,750-3,000$ & $3,336.85$ & $3,313.71$ \\
$-\mathrm{CH}$ (Alkane) & $3,000-2,700$ & $2,881.65$ & $2,885.51$ \\
$-\mathrm{C}=\mathrm{C}$ (Alkene) & $1,680-1,620$ & $1,643.35$ & $1,647.21$ \\
\hline
\end{tabular}

chromatography in agarose-bound Concanavalin A column was carried out to separate the residual mannan found along with glucan.

\subsection{FTIR Analysis}

The FTIR obtained for the third-hour samples implies presence of Carbohydrates (See Figs. 4 and 5). The broadband between approximately 3,600 and $3,200 \mathrm{~cm}^{-1}$ is the result of stretching vibrations of $\mathrm{O}-\mathrm{H}$ in the sugar residue of polysaccharides. The intense absorption at $3,000-2,700 \mathrm{~cm}^{-1}$ corresponds to medium stretching vibrations of $\mathrm{C}-\mathrm{H}$ which is a characteristic of carbohydrates. Infrared spectroscopy was applied for the structural characterization of $\beta$-glucan [26]. A comparison of main peaks of the FTIR spectra of $A$. bisporus and $P$. ostreatus is given in Table 1. A similar FTIR spectra has been obtained by other authors [3436] about the structure of $\beta$-glucan.

\subsection{Formulation of Value-Added Milk}

$2.5 \mathrm{~g}$ of the purified $\beta$-glucan samples from $P$. ostreatus and $A$. bisporus were taken together and were added to the soy milk in the ratio of 1:40. Palm sugar was ground and varied concentrations were added to it. Based on the aforementioned criteria, the optimal (based on color change) palm sugar concentration was $25 \mathrm{mg}$ per $100 \mathrm{ml}$ of the soy milk and glucan mixture.

\section{CONCLUSION}

In the present study, hot water extraction was carried out which yielded a high concentration of polysaccharides at the third hour of treatment. The extract obtained was then purified by DEAE chromatography, followed by affinity chromatography. The purified samples were subjected to FTIR analysis and the results confirmed the presence of $\beta$-glucan. The samples containing $\beta$-glucan were then added to milk containing palm sugar to produce value-added milk having significant health benefits. Moreover, the leftover part after extraction can be an excellent value addition for other food products like mayonnaise. This study can be further extended in the future by carrying out sensory analysis of the product and then successfully bringing out the product into the market for consumer acceptance.

\section{ACKNOWLEDGMENT}

The authors would like to thank the management of Kumaraguru College of Technology, Coimbatore, Tamil Nadu, for providing research facilities and resources to carry out this research. 


\section{AUTHOR CONTRIBUTIONS}

All authors made substantial contributions to conception and design, acquisition of data, or analysis and interpretation of data; took part in drafting the article or revising it critically for important intellectual content; agreed to submit to the current journal; gave final approval of the version to be published; and agree to be accountable for all aspects of the work. All the authors are eligible to be an author as per the international committee of medical journal editors (ICMJE) requirements/guidelines.

\section{FUNDING}

There is no funding to report.

\section{CONFLICTS OF INTEREST}

The authors report no financial or any other conflicts of interest in this work.

\section{ETHICAL APPROVALS}

This study does not involve experiments on animals or human subjects.

\section{REFERENCES}

1. Eweis DS, Abed F, Stiban J. Carbon dioxide in carbonated beverages induces ghrelin release and increased food consumption in male rats: implications on the onset of obesity. Obes Res Clin Pract 2017;11(5):534-43.

2. Vartanian LR, Schwartz MB, Brownell KD. Effects of soft drink consumption on nutrition and health: a systematic review and metaanalysis. Am J Public Health 2007;97:667-75.

3. Popkin BM, Armstrong LE, Bray GM, Caballero B, Frei B, Willett WC. A new proposed guidance system for beverage consumption in the United States. Am J Clin Nutr 2006;83:529-42.

4. Tandel KR. Sugar substitutes: health controversy over perceived benefits. J Pharmacol Pharmacother 2011;2(4):236

5. Chalupa-Krebzdak S, Long CJ, Bohrer BM. Nutrient density and nutritional value of milk and plant-based milk alternatives. Int Dairy J 2018;87:84-92.

6. Sethi S, Tyagi SK, Anurag RK. Plant-based milk alternatives an emerging segment of functional beverages: a review. J Food Sci Technol 2016;53:3408-23.

7. Dan Ramdath D, Padhi EMT, Sarfaraz S, Renwick S, Duncan AM Beyond the cholesterol-lowering effect of soy protein: a review of the effects of dietary soy and its constituents on risk factors for cardiovascular disease. Nutrients 2017;9:324.

8. Erdman J. Soy protein and cardiovascular disease: a statement for healthcare professionals from the nutrition committee of the AHA. Circulation 2000;102:2555-9.

9. Maleki Z, Jazayeri S, Eslami O, Shidfar F, Hosseini AF, Agah S, et al. Effect of soy milk consumption on glycemic status, blood pressure, fibrinogen and malondialdehyde in patients with non-alcoholic fatty liver disease: a randomized controlled trial. Complement Ther Med 2019;44:44-50.

10. Ahmad A, Anjum FM, Zahoor T, Nawaz H, Dilshad SMR. Beta glucan: a valuable functional ingredient in foods. Crit Rev Food Sci Nutr 2012;52:201-12.

11. Lam KL, Cheung PCK. Non-digestible long chain beta-glucans as novel prebiotics. Bioact Carbohydr Dietary Fibre 2013;2:45-64.

12. Mäkeläinen $H$, Anttila $H$, Sihvonen J, Hietanen RM, Tahvonen R, Salminen E, et al. The effect of $\beta$-glucan on the glycemic and insulin index. Eur J Clin Nutr 2007;61(6):779-85.
13. Liatis S, Tsapogas P, Chala E, Dimosthenopoulos C, Kyriakopoulos K, Kapantais E, et al. The consumption of bread enriched with betaglucan reduces LDL-cholesterol and improves insulin resistance in patients with type 2 diabetes. Diabetes Metab 2009;35(2):115-20.

14. Singdevsachan SK, Auroshree P, Mishra J, Baliyarsingh B, Tayung $\mathrm{K}$, Thatoi H. Mushroom polysaccharides as potential prebiotics with their antitumor and immunomodulating properties: a review. Bioact Carbohydr Dietary Fibre 2016;7:1-4.

15. Uddin Pk M, Sayful Islam M, Pervin R, Dutta S, Talukder RI, Rahman M. Optimization of extraction of antioxidant polysaccharide from Pleurotus ostreatus (Jacq.) P. Kumm and its cytotoxic activity against murine lymphoid cancer cell line. PLoS One 2019;14(1):e0209371.

16. Atila F, Owaid MN, Shariati MA. The nutritional and medical benefits of Agaricus Bisporus: a review. J Microbiol Biotechnol Food Sci 2017;2021:281-6.

17. Bobek P, Nosálová V, Cerná S. Effect of pleuran ( $\beta$-glucan from Pleurotus ostreatus) in diet or drinking fluid on colitis in rats. Nahrung 2001;45(5):360-3.

18. Smiderle FR, Olsen LM, Carbonero ER, Baggio CH, Freitas CS, Marcon $\mathrm{R}$, et al. Anti-inflammatory and analgesic properties in a rodent model of a $(1 \rightarrow 3),(1 \rightarrow 6)$-linked $\beta$-glucan isolated from Pleurotus pulmonarius. Eur J Pharmacol 2008;597(1-3):86-91.

19. Synytsya A, Míčková K, Synytsya A, Jablonský I, Spěváček J, Erban $\mathrm{V}$, et al. Glucans from fruit bodies of cultivated mushrooms Pleurotus ostreatus and Pleurotus eryngii: structure and potential prebiotic activity. Carbohydr Polym 2009;76(4):548-56.

20. Srikaeo K, Thongta R. Effects of sugarcane, palm sugar, coconut sugar and sorbitol on starch digestibility and physicochemical properties of wheat based foods. Int Food Res J 2015;22(3):923-9.

21. Chitisankul WT, Shimada K, Omizu Y, Uemoto Y, Varanyanond W, Tsukamoto C. Mechanism of DDMP-saponin degradation and maltol production in soymilk preparation. LWT Food Sci Technol 2015;64(1):197-204.

22. Wasser S. Medicinal mushrooms as a source of antitumor and immunomodulating polysaccharides. Appl Microbiol Biotechnol 2002;60:258-74.

23. Garriga M, Almaraz M, Marchiaro A, Nacional De La U, San P, Bosco $\mathrm{J}$, et al. Determination of reducing sugars in extracts of Undaria pinnatifida (harvey) algae by UV-visible spectrophotometry (DNS method). Actas Ing 2017;3:444.

24. Mecozzi M. Estimation of total carbohydrate amount in environmental samples by the phenol-sulphuric acid method assisted by multivariate calibration. Chemom Intell Lab Syst 2005;79(1-2):84-90.

25. Palczewska M, Batta G, Groves P. Concanavalin A-agarose removes mannan impurities from an extracellularly expressed Pichia pastoris recombinant protein. Cell Mol Biol Lett 2003;8(3):783-92.

26. Deniz DT, Çolak ÖF. Discrimination of Daedaleopsis nitida mushrooms that growing in different environments using fourier transform infrared spectroscopy. Sigma J Eng Nat Sci Mühendislik ve Fen Bilim Derg 2018;36(2):577-82.

27. Adebiyi AO, Oyedeji AA, Tedela PO. Effect of different drying methods on the nutritional quality of an edible mushroom-Pleurotus sajor-caju widely consumed in Nigeria. J Adv Food Sci Technol [Internet] 2018;42-6. Available via https://www.ikppress.org/index. php/JAFSAT/article/view/3746(Accessed 16 August 2021).

28. Kic P. Mushroom drying characteristics and changes of colour. In 17th International Scientific Conference: Engineering for Rural Development, Jelgava, Latvia, 2018.

29. Shaik J. Study on preliminary phytochemical screening and anti ulcer activity of Agaricus bisporus. J Pharmacogn Phytochem [Internet] 2018;7(5):2015-9. Available via https://www.phytojournal.com/ archives/2018.v7.i5.5856/study-on-preliminary-phytochemicalscreening-and-anti-ulcer-activity-of-ltemgtagaricus-bisporusltemgt (Accessed 23 July 2021).

30. Parihar S, Virani KD, Pithawala EA, Shukla MD, Lahiri SK, Jain NK, et al. Phytochemical screening, total phenolic content, antibacterial 
and antioxidant activity of wild edible mushroom Pleurotus ostreatus. Int Res J Pharm 2015;6(1):65-9.

31. Ikon GM, Udobre EA, Etang UE, Ekanemesang UM, Ebana RU, Edet UO. Phytochemical screening, proximate composition and antibacterial activity of oyster mushroom, Pleurotus ostreatus collected from Etim Ekpo in Akwa Ibom State, Nigeria. Asian Food Sci J 2018;6(2):1-10.

32. Pipriya S, Tiwari U. Evaluation of antibacterial potential \& phytochemical screening by the medicinal plant of Acorus calamus \& Agaricus bisporus \& their synthesis of herbal silver nanoparticles with different solvents. Int J Eng Res Technol 2019;8(5):158-69.

33. Roy DN, Azad AK, Sultana F, Anisuzzaman ASM, Khondkar P. Nutritional profile and mineral composition of two edible mushroom varieties consumed and cultivated in Bangladesh. J Phytopharm 2015;4(4):217-20.

34. Ashraf Khan A, Gani A, Masoodi FA, Mushtaq U, Silotry Naik A. Structural, rheological, antioxidant, and functional properties of $\beta$ glucan extracted from edible mushrooms Agaricus bisporus, Pleurotus ostreatus and Coprinus attrimentarius. Bioact Carbohydrates Diet Fibre 2017;11:67-74.

35. Ramadhani I, Larissa D, Yuliani Y, Amir M, Kusmiati K. Extraction, characterization, and biological toxicity of $\beta$-glucans from
Saccharomyces cerevisiae isolated from ragi. J Microb Syst Biotechnol 2020;2(2):35-43.

36. Yunita EP, Yuniar AM, Kusumastuty I, Maghfirotun A, Handayani D. The effects of B-glucan extract from oyster mushroom (Pleurotus ostreatus) on expression of serum malondialdehyde in Sprague Dawley rats induced by HFHF diet. J Phys Conf Ser 2020;1665:12035.

\section{How to cite this article:}

Kumaresan K, Gopalakrishnan S, Sivasamy RK, Alagu T, Sathishkumar T. Fortification of soy milk with prebiotic natural $\beta$-glucan derived from edible mushrooms Pleurotus ostreatus and Agaricus bisporus. J Appl Biol Biotech 2022; 10(01):157-163. 